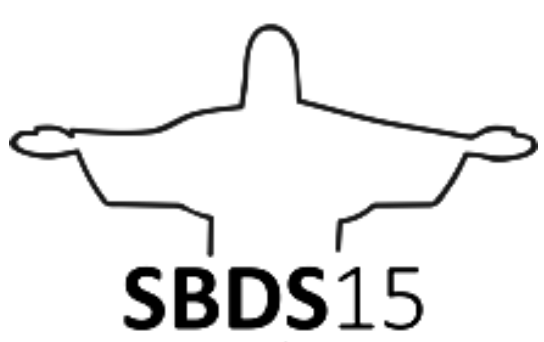

5 SIMPÓSIO DE

DESIGN SUSTENTAVEL

Rio de Janeiro, 11 de novembro a 13 de novembro de 2015

\title{
DESIGN E MATERIAIS: DESENVOLVIMENTO DE BIOCOMPÓSITOS A PARTIR DA CASCA DE ARROZ E DO RESÍDUO DE PAPEL EM MATRIZ POLIURETANA VEGETAL À BASE DE MAMONA
}

\author{
Eliana Paula Calegari \\ Universidade Federal do Rio Grande do Sul \\ elianapaulac@gmail.com \\ Clarissa Coussirat Angrizani \\ Universidade Federal do Rio Grande do Sul \\ cangrizani@hotmail.com \\ Jussara Smidt Porto \\ Universidade Federal do Rio Grande do Sul \\ jussara.porto@ufrgs.br \\ Bábara Zanella \\ Universidade Federal do Rio Grande do Sul \\ barbara_zanella@hotmail.com \\ Sandro Campos Amico \\ Universidade Federal do Rio Grande do Sul \\ amico@ufrgs.br \\ Lauren da Cunha Duarte \\ Universidade Federal do Rio Grande do Sul \\ lauren.duarte@ufrgs.br \\ Branca Freitas de Oliveira \\ Universidade Federal do Rio Grande do Sul \\ branca@ufrgs.br
}

\begin{abstract}
Resumo
Com o objetivo de desenvolver novos materiais que estejam de acordo com a perspectiva da sustentabilidade, neste estudo foram produzidos biocompósitos a partir da casca de arroz e de resíduos do papel. Como matriz, utilizou-se o
\end{abstract}


poliuretano vegetal á base de óleo da mamona, proveniente de fonte renovável. Foram confeccionados biocompósitos com $80 \%$ de casca de arroz e $20 \%$ de resina poliuretana vegetal, e outro com $80 \%$ de resíduo de papel com $20 \%$ de resina poliuretana vegetal. Para fins de comparação, foram desenvolvidos biocompósitos com matriz polimérica de poliéster, com as mesmas proporções de reforço dos compósitos com matriz poliuretana vegetal. Para o processamento das placas dos biocompósitos foi utilizada a moldagem por compressão. Como resultado, foram obtidas as placas de biocompósitos com $80 \%$ de materiais oriundos de resíduos, como é o caso da casca de arroz e do papel. Os novos materiais desenvolvidos possuem estética visual diferenciada, pelo fato de que a casca de arroz e o papel apresentarem-se visíveis. A possibilidade de utilização de até $80 \%$ de carga (casca de arroz e resíduo de papel) imersa em matriz polimérica é uma grande vantagem quanto à quantidade de resíduos a ser utilizada, o que indica serem os biocompósitos desenvolvidos nesta pesquisa, materiais com apelo ecológico.

Palavras-chave: biocompósito, casca de arroz, resíduo de papel, poliuretano vegetal, design de produto.

\begin{abstract}
In order to develop new materials that comply with the perspective of sustainability in this study were produced biocomposites from rice husk and waste paper. As a matrix, it is used castor oil based polyurethane, which comes from renewable sources. The methodology consists in an experimental search thereby biocomposites were made with $80 \%$ of rice hulls and $20 \%$ of vegetable polyurethane resin, and one with $80 \%$ paper waste with $20 \%$ of vegetable polyurethane resin. For comparison purposes, biocomposites were developed with polymeric polyester matrix, with the same proportions of reinforcement composite with vegetable polyurethane matrix. For the processing of biocomposites plates the compression molding was used. As a result were obtained sheets of biocomposites with $80 \%$ of materials from waste, as is the case of rice husks and paper. The new materials have the distinctive visual compared to traditional materials such as polymers, metals, ceramics, by the fact that the rice husks and paper present are visible, which makes environmentally friendly materials with biocomposites call.
\end{abstract}

Keywords: biocomposite, rice hulls, waste paper, vegetable polyurethane, product design.

\title{
1. INTRODUÇÃO
}

Atualmente, há inúmeros pesquisadores que trabalham na próxima geração de materiais, processos e ferramentas que permitirão o desenvolvimento de novos projetos voltados à preservação ambiental. Essa inovação em materiais é necessária para resolver os problemas e as necessidades do futuro, principalmente com a preocupação das questões ecológicas e com a escassez de materiais provenientes de 
fontes não renováveis. Cada vez mais a abordagem no desenvolvimento de novos materiais compreende todo o ciclo de vida do mesmo, em que considera os impactos causados desde a extração da matéria-prima até o destino final do produto (CARVALHO, 2011).

Neste contexto materiais com ciclo de vida mais enxuto e advindos de fontes renováveis estão sendo pesquisados, como é o caso do polietileno verde da Braskem (BRASKEM $\left.^{\circledR}, 2015\right)$. Além disso, em diversas pesquisas para o desenvolvimento de novos materiais, são utilizados materiais considerados resíduos. Como exemplo, podese citar o trabalho desenvolvido por Borsoi et al. (2011), que desenvolveram materiais compósitos de fibras de algodão/poliestireno com um percentual mássico de 10 e $20 \%$ em fibras de algodão oriundas do resíduo de uma indústria têxtil, através dos processos de extrusão e injeção, e observaram uma melhora significativa nas propriedades de flexão, impacto e tração em relação ao polímero puro.

Portanto, com o intuito de proporcionar melhor aproveitamento dos resíduos gerados pela atividade arrozeira e gráfica, quais seja da casca de arroz e aparas de papel, este estudo vem sugerir o uso destes resíduos como reforço em material polimérico proveniente do óleo da mamona e da resina poliéster, a fim de gerar novos materiais e estes serem aplicados no design de produtos.

\section{REFERENCIAL TEÓRICO}

\subsection{Compósitos}

De acordo com a Norma American Society for Testing and Materials - ASTM D3878 - 95, a definição de material compósito consiste em uma substância constituída de dois ou mais materiais, insolúveis entre si, que são combinados para formar um material de engenharia com certas propriedades que não se encontram nos materiais isoladamente. A matriz tem como função transferir a carga para as fibras, proteger as fibras da abrasão e ataque ambiental (MAHAJAN, AHER, 2012).

Os compósitos têm sido usados pelo homem desde a antiguidade, como exemplo, a argila reforçada com galhos de árvores, usada em construções feitas pelos antigos egípcios, há 3.000 anos, é conhecida como sendo o primeiro compósito na história humana, assim, os primeiros compósitos utilizados eram oriundos de fontes naturais (SAPUAN; MALEQUE, 2005). Com o desenvolvimento da humanidade e o avanço tecnológico, materiais com melhor desempenho, tanto metais como cerâmicas e polímeros, contendo fibras sintéticas, foram largamente desenvolvidos e usados, havendo uma diminuição do interesse por compósitos de materiais naturais (GAY et al., 2002) devido, principalmente, as propriedades mecânicas limitadas.

Os materiais compósitos de alto desempenho surgiram no segmento aeroespacial na década de 1970, mas atualmente tem havido grande interesse no segmento automotivo, esportivo e na indústria civil (MAHAJAN, AHER, 2012). Devido à preocupação da sociedade com a redução de impactos ambientais, começaram a surgir tecnologias "verdes", assim, esforços têm sido feitos para o desenvolvimento de materiais alternativos que sejam amigáveis ao meio ambiente. Além disso, devido à possibilidade de esgotamento futuro dos recursos petrolíferos juntamente com o aumento da regulamentação ambiental, estão surgindo novos materiais e produtos que visam reduzir os impactos no meio ambiente. Deste modo, sugiram os 
biocompósitos, que segundo Mohanty et al. (2005) são materiais que possuem pelo menos um tipo de material oriundo de fontes naturais e renováveis, que geralmente são as fibras.

Neste sentido, o desenvolvimento de estudos na área de compósitos reforçados com fibras naturais teve grande impulso. Um dos principais fatores que favorecem o uso de fibras naturais é a sua abundância na natureza, baixa densidade, menor abrasão, custo, e o fato de que provêm de recursos. Assim, estudos avançados em compósitos poliméricos reforçados com fibras naturais estão sendo motivados, em parte, pela necessidade de proteção ao meio ambiente associada à viabilidade econômica de aproveitamento de resíduos, o que pode originar materiais com novas propriedades mecânicas e baixo custo (MOURA, 2014).

\subsection{A casca de arroz}

No Brasil são geradas grandes quantidades de resíduos agroindustriais provenientes da monocultura, com a finalidade de obtenção de produtos alimentícios em larga escala. Em relação a estes resíduos destaca-se a casca de arroz oriunda do beneficiamento do arroz, principalmente, na Região Sul do país. Conforme pesquisa realizada pelo Ministério da Agricultura, Pecuária e Abastecimento (MAPA) da safra de 2012/2013, o estado do Rio Grande do Sul foi responsável por $64,35 \%$ da produção nacional, seguido de Santa Catarina, Mato Grosso e Maranhão, responsáveis por $8,25 \%, 5,36 \%$ e $4,42 \%$, respectivamente. Além disso, segundo dados do MAPA, foram produzidos 11,9 milhões de toneladas de arroz, e destes $20 \%$ são considerados rejeitos, ou seja, aproximadamente 3,38 milhões de toneladas, assim, a casca representa o subproduto mais volumoso da cultura do arroz_(SILVA et al., 2012).

Mayer et al. (2006) explica que o destino primário da casca de arroz é a compostagem, o que reduz a sua carga orgânica. No entanto, este método é empregado de forma indireta pela maioria dos produtores, já que boa parte da casca gerada é depositada no solo como única forma de disposição deste resíduo. Um problema deste tratamento é que a casca de arroz demora aproximadamente 5 anos para decompor-se gerando grande quantidade de metano. Além disso, a casca apresenta baixa densidade, em torno de $130 \mathrm{~kg} / \mathrm{m}^{3}$, o que resulta em um grande volume necessário para a sua disposição. Outro destino para a casca de arroz é a queima a céu aberto, emitindo grande quantidade de monóxido e dióxido de carbono. No que diz respeito ao emprego da casca de arroz em biocompósitos, Caraschi et al. (2009) comentam que o aproveitamento deste resíduo como material de reforço para matrizes poliméricas resultou em materiais com desempenho bastante superior às amostras sem reforço.

\subsection{Resíduo do papel}

Em relação ao papel, conforme o Portal dos Resíduos Sólidos (2015) o consumo deste material no Brasil está em torno de 6.000 .000 t/ano. Os impactos da produção do papel são maiores que os de sua disposição pós-consumo. Como o papel é biodegradável, a maior preocupação está na derrubada de árvores e plantio de "monoculturas" para sua produção e nos resíduos gerados durante seu processo de fabricação. Desta forma, incentivos para a reciclagem abrangem não só aspectos econômicos como, também, de sustentabilidade. Diante disso, o setor de papéis vem apresentando um aumento significativo no uso de reciclados, no ano de 2000 , o uso de 
recicláveis representou $45 \%$ da produção mundial de papel. No Brasil, apenas $37 \%$ do papel produzido é reciclado, de todo o papel reciclado, $80 \%$ é destinado à confecção de embalagens, $18 \%$ para papéis sanitários e apenas $2 \%$ para a impressão. Estima-se que na fabricação de aproximadamente uma tonelada de papéis corrugados, são necessárias, aproximadamente, 2 toneladas de madeira (o equivalente a cerca de 15 árvores), 44 a 100 mil litros de água e de 5 a 7,6 mil KW de energia. A produção desta mesma quantidade de papel gera $18 \mathrm{Kg}$ de poluentes orgânicos descartados nos efluentes e $88 \mathrm{Kg}$ de resíduos sólidos. Os poluentes são compostos por fibras, breu (material insolúvel) e celulose (de difícil degradação). Já no processo de reciclagem, o volume de água utilizado cai para 2 mil litros e o consumo de energia cai para 2,5 mil KW. Reciclar e reutilizar o papel, ao invés de fabricá-lo a partir da celulose, pode levar a uma redução de consumo de energia, emissão de poluentes e do uso da água, além de redução da percentagem de papel descartado como resíduo sólido.

\subsection{Poliuretano vegetal à base de óleo de mamona}

Uma alternativa para o desenvolvimento de biocompósitos é o uso de resinas provenientes de fontes renováveis, como a derivada do óleo de mamona, que teve origem nos primeiros trabalhos propostos na década de 1940. Conforme Oliveira (2011) a resina poliuretana do óleo de mamona não é agressiva ao meio ambiente, pois é isenta de solventes, ou seja, não apresenta materiais voláteis e metais pesados em sua composição, assim, a resina é atóxica. A autora salienta que as poliuretanas à base de óleo de mamona diferem muito das derivadas de petróleo, pois sua matériaprima é proveniente de recursos vegetais renováveis, sendo bastante resistentes aos agentes agressivos, tais como, ácidos, álcalis e bases. Além disso, ao contrário das poliuretanas de petróleo, as de base vegetal não são inflamáveis e, quando queimados, não emitem gases tóxicos. A poliuretana derivada do óleo de mamona é um polímero que possui apelo ecológico, principalmente por não se originar de fontes petrolíferas. Oliveira (2011) afirma que este material vem sendo utilizado em várias áreas, tais como o setor de telecomunicações, redes de telefonia, medicina, eletroeletrônicos, automobilístico, tintas e vernizes, adesivos, espumas e elastômeros.

A resina poliuretana vegetal à base de óleo de mamona apresentam-se como um líquido viscoso, obtido pela compressão das sementes da mamona ou por extração com solventes (VILAR, 1993). Esta resina é formada por dois componentes: um prépolímero com terminação isocianato e um poliol que sintetizados por poliadição, reagem entre si, formando um composto poliuretano. Na mistura dos componentes, quanto maior for à proporção do poliol, mais flexível fica a estrutura da resina. Enquanto que, se houver maior concentração de pré-polímero, mais rígida torna-se a estrutura (GODOY, 2007). A polimerização final ocorre em torno de 24 horas e sua secagem ao toque entre 10 e 30 minutos, dependendo da umidade e temperatura ambiente, possui viscosidade de 7,5 Pa.s e densidade de $0,959 \mathrm{~g} / \mathrm{cm}^{3}$ ambas a $25{ }^{\circ} \mathrm{C}$ (ARAÚJO et al. 2002).

Carvalho et al. (2002) desenvolveram biocompósitos com fibras de sisal e poliuretano derivado de óleo de mamona. Neste estudo foram avaliadas as propriedades mecânicas de tração. Os compósitos com fibras contínuas e alinhadas mostraram o melhor desempenho, com acréscimo no módulo (88 vezes) e na resistência ( 6 vezes) em relação à matriz pura. Em outro trabalho semelhante, Sousa (2013) produziu e caracterizou compósitos poliméricos utilizando como matriz a resina 
poliuretana à base de óleo de mamona reforçada com fibras de rami, sisal e bucha vegetal com teor de fibra de $25 \%, 35 \%, 45 \%$ e $55 \%$, distribuídas aleatoriamente. Os compósitos foram produzidos por moldagem por compressão à temperatura ambiente. A partir do ensaio de tração foi determinada a resistência à tração, o módulo de elasticidade e a deformação máxima. Segundo a autora, as melhores propriedades apresentaram-se nos compósitos com $45 \%$ de reforço de fibra de sisal, os reforçados com fibra de rami também apresentaram módulo de elasticidade elevado (23 GPa).

\section{MATERIAIS E MÉTODOS}

Para o desenvolvimento dos biocompósitos ${ }^{1}$ foram utilizados como matriz o poliuretano vegetal à base de óleo de mamona e a resina poliéster. Como reforço, foi empregada a casca de arroz e o resíduo do papel. O intuito de utilizar duas matrizes é que as mesmas apresentam propriedades organolépticas diferentes, a resina poliuretana é flexível e a resina poliéster é rígida.

A resina poliuretana foi doada pela empresa Imperveg $^{\circledR}$ e a resina poliéster ortoftálica foi doada pela empresa Agrale ${ }^{\circledR}$. O papel é um resíduo proveniente da Gráfica da Universidade Federal do Rio Grande do Sul e a casca de arroz é um resíduo da agroindústria do Rio Grande do Sul. Com estes materiais foram desenvolvidos quatro composições de bicompósitos contendo as porcentagens em volume de materiais conforme mostra a tabela 1.

Tabela 1 - Composição dos compósitos.

\begin{tabular}{c|c|c|c|c}
\hline Biocompósito & $\begin{array}{c}\text { Material da } \\
\text { matriz }\end{array}$ & $\begin{array}{c}\text { Material da } \\
\text { carga }\end{array}$ & $\begin{array}{c}\text { Fração volumétrica } \\
\text { da matriz }\end{array}$ & $\begin{array}{c}\text { Fração } \\
\text { volumétrica do } \\
\text { reforço }\end{array}$ \\
\hline $\begin{array}{c}\text { Resina PU } \\
\text { mamona/papel }\end{array}$ & $\begin{array}{c}\text { Resina PU } \\
\text { mamona }\end{array}$ & Papel & $20 \%$ & $80 \%$ \\
\hline $\begin{array}{c}\text { Resina PU } \\
\text { Mamona/casca de } \\
\text { arroz }\end{array}$ & $\begin{array}{c}\text { Resina PU } \\
\text { mamona }\end{array}$ & Casca de arroz & $20 \%$ & $80 \%$ \\
\hline $\begin{array}{c}\text { Poliéster/papel } \\
\text { Poliéster/casca de } \\
\text { arroz }\end{array}$ & Poliéster & Papel & $20 \%$ & $80 \%$ \\
\hline
\end{tabular}

Fonte: Elaborado pelos autores, com base na pesquisa realizada.

Cabe destacar que foi optado por utilizar $80 \%$ de material de reforço para os biocompósitos, pois assim há um maior aproveitamento dos resíduos de papel e da casca de arroz. Em experimentos preliminares foi testada a composição de $50 \%, 60 \%$, $70 \%, 80 \%$ e $90 \%$ de reforço, sendo que o melhor resultado foi o biocompósito com $80 \%$ de casca de arroz/papel.

\subsection{Microscopia eletrônica de varredura (MEV)}

Com o intuito de verificar a morfologia superficial da casca de arroz e do papel foi realizada a Microscopia Eletrônica de Varredura (MEV). Segundo Canevarolo (2004)

1 Os biocompósitos foram desenvolvidos no Laboratório de Materiais Poliméricos (Lapol) junto ao Grupo de Materiais Compósitos e Nanocompósitos Poliméricos (GCOMP) da Universidade Federal do Rio Grande do Sul. 
esta ferramenta permite o estudo da estrutura fina e da morfologia de materiais. Utilizou-se o equipamento JSM-6060, da marca Jeol ${ }^{\circledR}$, do Laboratório de Seleção de Materiais (LDSM) da UFRGS, em que a magnificação da imagem chega à ordem de 30.000 vezes e as condições analíticas para obtenção de imagens do tipo backsacttered electron (BSE) foram de $15 \mathrm{KeV}$ para a aceleração do feixe de elétrons e magnificação máxima da ordem de 4.000 vezes.

\subsection{O processamento dos biocompósitos}

O método utilizado para o processamento dos biocompósitos foi à moldagem por compressão. A moldagem por compressão consiste em transformar um material, depositado na cavidade de um molde, em uma peça de forma definida, através da aplicação de pressão com ou sem aquecimento (CANEVAROLO, 2002). Este é um dos processos muito utilizados para a conformação de compósitos devido ao baixo custo.

O processamento dos biocompósitos foi iniciado com a preparação dos materiais de reforço. Nesta etapa, a casca de arroz e o papel foram secos em estufa com temperatura e tempo controlados, conforme é possível observar na tabela 2.

Tabela 2 - Temperatura e período de secagem dos materiais de reforço.

\begin{tabular}{c|c}
\hline Biocompósito & Secagem da carga em estufa \\
\hline Resina PU mamona/papel & $60 \mathrm{C}^{\circ}$ por $2 \mathrm{~h}$ \\
\hline $\begin{array}{c}\text { Resina PU } \\
\text { Mamona/casca de arroz }\end{array}$ & $100 \mathrm{C}^{\circ}$ por $24 \mathrm{~h}$ \\
\hline Poliéster/papel & $60 \mathrm{C}^{\circ}$ por $2 \mathrm{~h}$ \\
\hline Poliéster/casca de arroz & $100 C^{\circ}$ por $24 \mathrm{~h}$ \\
\hline
\end{tabular}

Fonte: Elaborado pelos autores, com base na pesquisa realizada.

Após a secagem, os materiais da matriz e do reforço foram pesados, misturados e depositados em um molde metálico nas dimensões de $17 \mathrm{~cm} \times 27 \mathrm{~cm}$, conforme podese visualizar na figura 1.

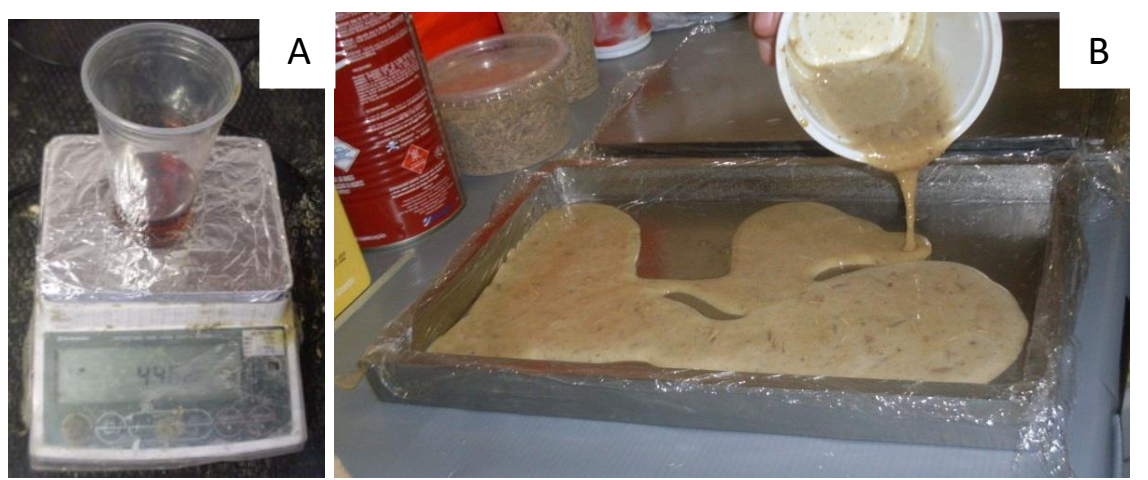

Figura 1 - Preparação dos materiais: A) Pesagem e B) Materiais sendo depositados no molde. Fonte: Elaborado pelos autores, com base na pesquisa realizada.

Na sequência, o molde foi fechado e colocado na prensa hidráulica. Na tabela 3 é possível visualizar o período em que o molde permaneceu na prensa bem como a temperatura utilizada para o processamento de cada biocompósito. Foi necessário utilizar pressões diferentes de acordo com o tipo de matriz, para a resina poliuretana 7 bar e para a poliéster 3 bar, devido as diferentes propriedades reológicas destes materiais. 
Tabela 3 - Condições de processamento dos biocompósitos.

\begin{tabular}{c|c}
\hline Biocompósito & Processamento \\
\hline Resina PU mamona/papel & Durante 24h - Temp. ambiente \\
\hline Resina PU & Durante 24h - Temp. ambiente \\
Mamona/casca de arroz & \\
\hline Poliéster/papel & Durante $75 \mathrm{~min}-80 \mathrm{C}^{\circ}$ \\
\hline Poliéster/casca de arroz & Durante $75 \mathrm{~min}-80 \mathrm{C}^{\circ}$ \\
\hline
\end{tabular}

Fonte: Elaborado pelos autores, com base na pesquisa realizada.

Como pode ser visualizado na tabela 3, foram utilizadas diferentes temperaturas e períodos para o processamento dos biocompósitos. Isso se deve ao fato de que os materiais do reforço e da matriz apresentam naturezas diferentes, o que está relacionado à temperatura a qual se pode processá-los sem deteriorar suas propriedades. Após o período de processamento, as placas foram retiradas do molde.

\section{RESULTADOS}

\subsection{Microscopia eletrônica de varredura (MEV)}

Na microscopia eletrônica de varredura foi possível analisar a superfície externa e interna da casca de arroz, e do resíduo do papel, o que se torna importante para avaliar a aderência da matriz no reforço. Desta forma, na figura 2, observam-se as imagens via MEV da casca de arroz, em que, nas imagens $A, B$ e C, é possível visualizar a superfície rugosa da casca além de espinhos que podem contribuir para a adesão interfacial entre a matriz e o reforço. Em relação à superfície interna da casca de arroz, como pode ser vista na imagem $\mathrm{C}$, esta possui textura menos rugosa. De forma geral, devido à textura rugosa e os espinhos da parte externa da casca, acredita-se que há boa adesão do polímero na casca de arroz.
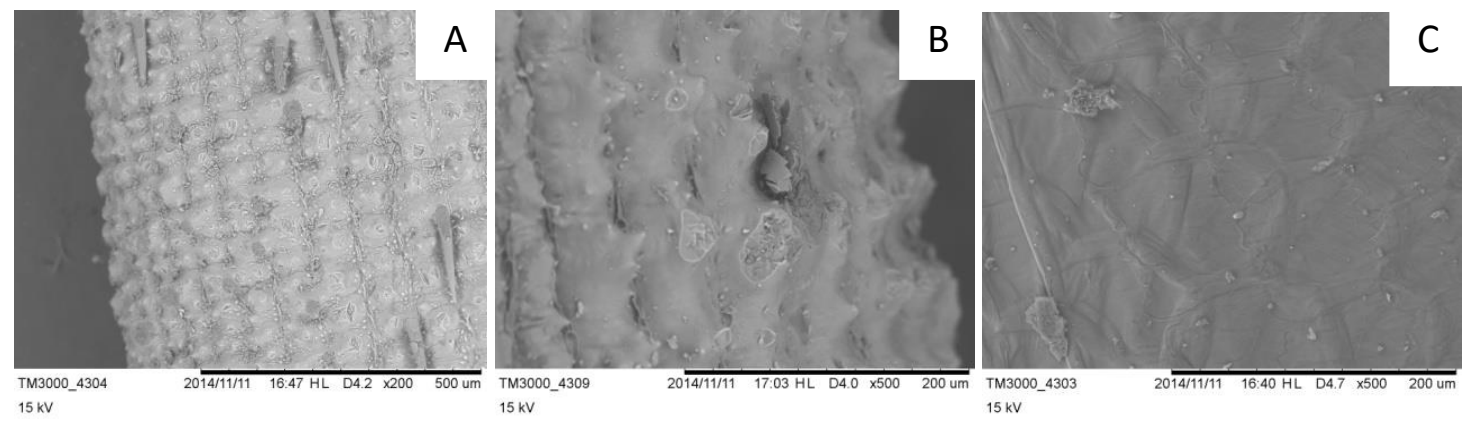

Figura 2 - Microscopia eletrônica de varredura da casca de arroz: A) e B)Parte externa da casca de arroz e C) Parte interna da casca de arroz.

Fonte: Elaborado pelos autores, com base na pesquisa realizada.

Em relação ao resíduo do papel, pode-se observar na figura 3 que este material é fibroso e que apresenta vazios entre as fibras. Estes espaços na estrutura do papel podem contribuir na adesão entre a fibra e a matriz na medida em que o material polimérico penetra nos vazios. 


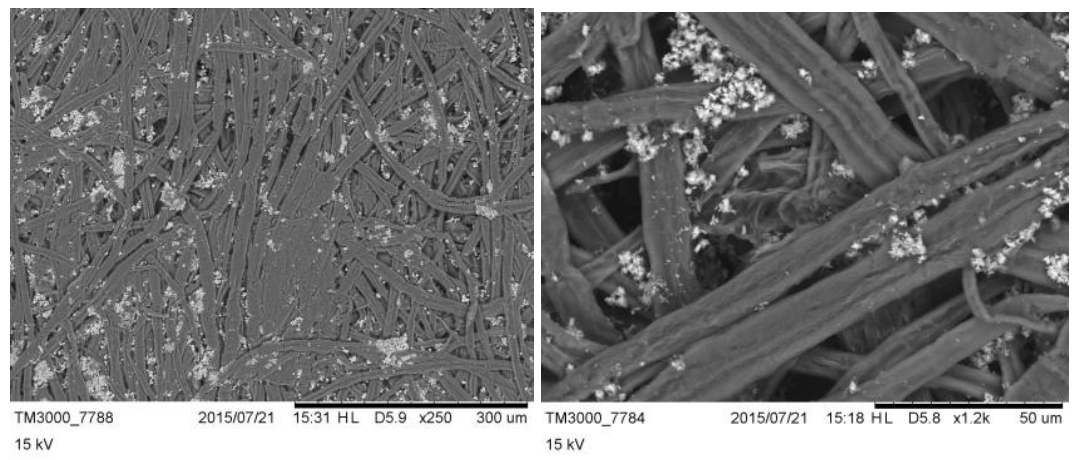

Figura 3 - Microscopia eletrônica de varredura do resíduo do papel.

Fonte: Elaborado pelos autores, com base na pesquisa realizada.

\subsection{Biocompósitos}

O processamento dos biocompósitos, por meio da moldagem por compressão, resultou em placas uniformes, em que, pode-se constatar visualmente que a matriz aderiu o reforço. Na figura 4 é possível observar os biocompósitos constituídos de resina poliuretana vegetal com casca de arroz e resina poliuretana vegetal com papel, e na figura 5 , pode-se visualizar os biocompósitos constituídos de resina poliéster com casca de arroz e poliéster com papel.

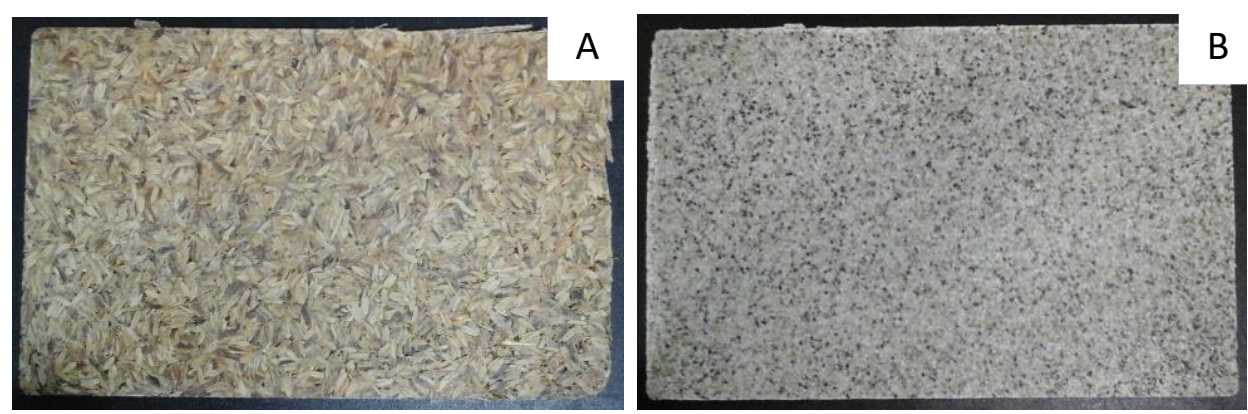

Figura 4 - Biocompósitos: A) Poliuretano/casca de arroz e B) Poliuretano/papel.

Fonte: Elaborado pelos autores, com base na pesquisa realizada.
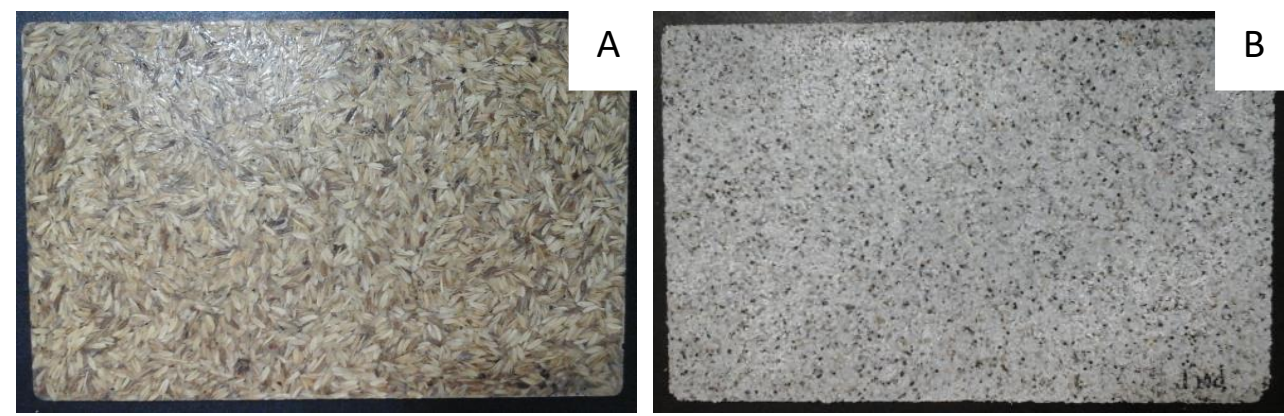

Figura 5 - Biocompósitos: A) Poliéster/casca de arroz e B) Poliéster/papel.

Fonte: Elaborado pelos autores, com base na pesquisa realizada.

Em relação às placas de poliuretano vegetal/casca de arroz e poliuretano vegetal/papel, esta última apresentou um aspecto visual mais uniforme devido aos vazios aparentes na superfície do biocompósito com casca de arroz, como pode ser observado na figura 6 . No entanto, uma possível solução para a diminuição dos vazios seria triturar ou moer a casca de arroz. 


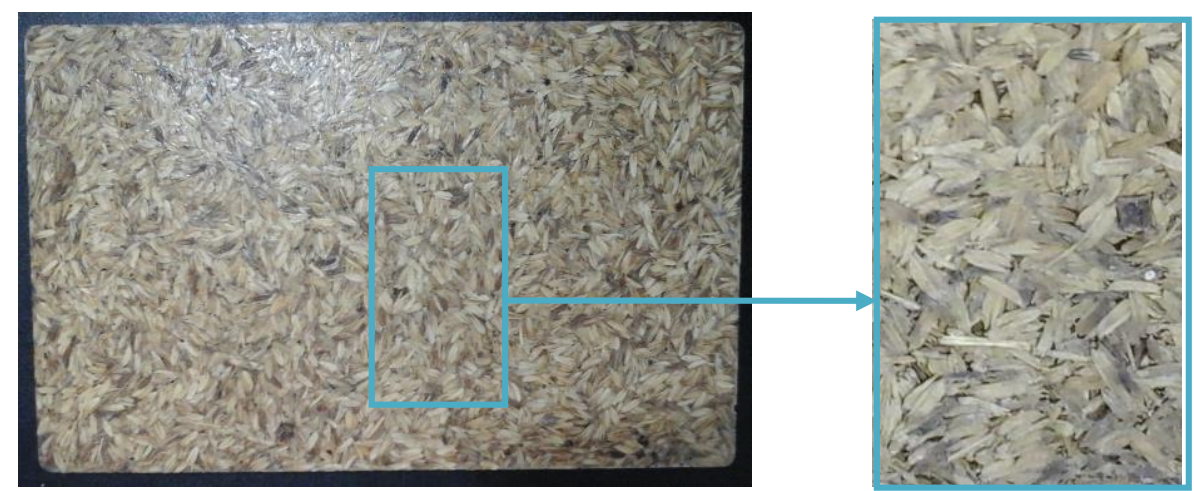

Figura 6 - Vazios aparentes no biocompósito de poliuretano vegetal com casca de arroz.

Fonte: Elaborado pelos autores, com base na pesquisa realizada.

Os compósitos moldados com poliéster (poliéster/casca de arroz e poliéster/papel) apresentaram um aspecto visual mais satisfatório em relação aos moldados com matriz de poliuretano vegetal, provavelmente devido ao fato da resina poliéster somente endurecer após misturá-la com o iniciador, e a resina poliuretana ter a característica de expandir durante a reação do poliol e do isocianato formando vazios entre a casca de arroz e a matriz.

Para fins de comparação visual, na figura 7 é possível visualizar os biocompósitos com diferentes matrizes. No que diz respeito aos compósitos constituídos pelo reforço de casca de arroz, o que possui matriz em poliéster possui a aparência mais uniforme, pois aparentemente, a resina preencheu toda a placa, e a coloração da casca de arroz foi preservada, pois o poliéster é transparente e o poliuretano vegetal é esverdeado. Em relação os biocompósitos com reforço de papel, ambos com matriz de poliuretano vegetal e poliéster aparentam estarem uniformes. A placa de poliuretano vegetal com papel apresentou coloração levemente esverdeada devido à cor verde desta resina.
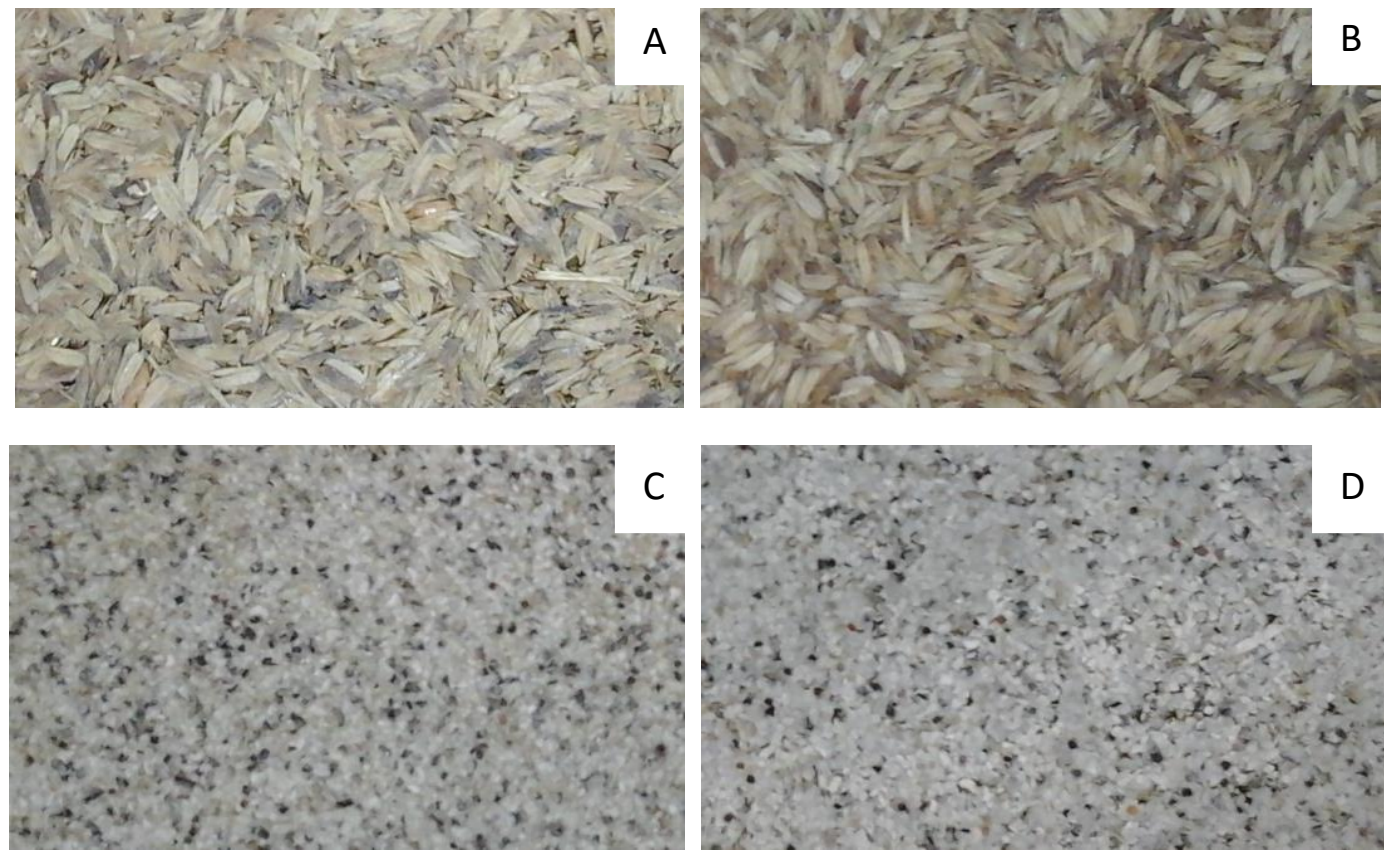

Figura 7 - Comparação visual das placas: A) Poliuretano vegetal/casca de arroz, B) Poliéster/casca de arroz, C) Poliuretano vegetal/papel e D) Poliéster/papel.

Fonte: Elaborado pelos autores, com base na pesquisa realizada. 
Cabe salientar, que o material de reforço, tanto a casca de arroz quanto o papel, estão aparentes no material. Desta forma, devido ao fato da casca de arroz estar visível no biocompósito, este remete ao natural, ao ecológico e a sustentabilidade, o que seria interessante explorar estas características em um projeto de design sustentável em móveis, decoração, divisórias, por exemplo. Em relação aos compósitos com reforço de papel, a aparência remete às rochas ornamentais de granulometria fina, como granito, desse modo, estes materiais poderiam ser empregados em painéis e revestimentos. Outro ponto que diferencia os compósitos em relação aos materiais da matriz é a flexibilidade/rigidez, ou seja, aparentemente os compósitos de poliuretano vegetal são mais flexíveis e os de poliéster mais rígidos, o que influencia no tipo de aplicação para estes materiais.

\section{CONCLUSÃO}

Os novos materiais desenvolvidos neste trabalho, através da moldagem por compressão, possuem o visual diferenciado, quando comparados aos materiais tradicionais como polímeros, metais e cerâmicas, pelo fato de que a casca de arroz e o papel estarem visíveis. Dessa forma, a aparência dos biocompósitos remete ao natural, principalmente os reforçados com casca de arroz, o que os tornam materiais com apelo ecológico. A semelhança visual entre o compósito com papel e granitos ornamentais de granulometria fina, pode favorecer o uso deste material para superfícies, onde a elevada densidade do material lítico impossibilite seu uso.

Em relação ao aspecto visual, a combinação da casca de arroz com a resina poliuretana foi a menos interessante, pois apresentou vazios na placa. A resina poliéster utilizada neste trabalho apresentou a desvantagem de ser de origem de fonte não renovável, mas foi a que resultou em melhor uniformidade e compatibilidade com os reforços, o que pode ser interessante realizar novos experimentos com outros tipos de resinas de origem renovável.

Os biocompósitos desenvolvidos nesta pesquisa podem ser empregados em um projeto de design orientado à sustentabilidade, pois são utilizados materiais de reforço provenientes de resíduos, como a casca de arroz e o papel, a resina poliuretana vegetal à base de óleo de mamona, constituinte da matriz, é de fonte renovável, além disso, o aspecto do material resultante remete ao conceito ecológico.

\section{REFERÊNCIAS}

ASTM D3878 - 95. Standard terminology of high - modulus reinforcing fibers and their composites. 1995.

ARAÚJO, C. R.; PERLAZA, L. C.; MOTHÉ, C. G. Thermal properties of commercial and castoir oil polyurethane composites with curaua fiber. In: Fouth International Symposium on Natural Polymers and Composites, São Paulo, 2002.

BRASKEM. Polietileno verde. Disponível em: <www.braskem.com.br/site.aspx/Comoe-Produzido $>$. Acesso em 10 de maio de 2015.

CANEVAROLO, J. S. V. Técnicas de caracterização em polímeros. São Paulo: Artliber, 2004.

CARASCHI J. C.; LEÃO A. L.; CHAMMA P. V. C. Avaliação de painéis produzidos a partir de resíduos sólidos para aplicação na arquitetura. Polímeros: Ciência e Tecnologia, v. 19, n. 1, p. 47-53, 2009. 
CARVALHO, L. F. M. Tratamentos de fibras de carnaúba [copernicia prunífera (miller) H. E. moore] para o desenvolvimento de compósito biodegradável com matriz de polihidroxibutirato. Doutorado - Programa de Pós-Graduação em Ciência e Engenharia de Materiais, UFRN, Natal, 2011.

CARVALHO, L. H. et al. Tensile properties of sisal reinforced polyurethane. In: Internacional Symposium on Natural Polymers and Composites, São Pedro. Anais, São Carlos: USP. p. 542-546, 2002.

GAY, D.; HOA, S. V.; TSAI, S. W. Composite materials: design and applications. London: CR PRESS, 2002.

GODOY, J. Estudo de um novo compósito madeira / resina poliuretano para o desenvolvimento de um isolador híbrido. Dissertação (Mestrado). Escola de Engenharia de São Carlos. Universidade de São Paulo, 2007.

MAHAJAN, G.V.; AHER, V. S. Composite Material: A Review over Current Development and Automotive Application. International Journal of Scientific and Research Publications, Volume 2, Issue 11, 2012.

MAYER, F. D.; HOFFMANN, R.; RUPPENTHAL, J. E. Gestão Energética, Econômica e Ambiental do Resíduo Casca de Arroz em Pequenas e Médias Agroindústrias de Arroz. XIII SIMPEP - Bauru, SP, Brasil, 06 a 08 de novembro de 2006.

MOHANTY, A. K.; MISRA, M.; DRZAL, L. T.; SELKE, S. E.; HARTE, B. R.; HINRICHEN, H. Natural Fibers, Biopolymers, and Biocomposites: An Introduction. Taylor \& Francis, 2005.

MOURA, A. DA S. Estudo comparativo das propriedades mecânicas e térmicas entre compósitos de PHB (Polihidroxibutirato) reforçados com casca de arroz ou fibra de coco. Dissertação (Mestrado). Programa de Pós-Graduação em Integridade de Materiais da Engenharia da Faculdade Gama e Faculdade de Tecnologia da Universidade de Brasília, Brasília, 2014.

OLIVEIRA, A. K. F. de. Estudo da viabilidade técnica de utilização do compósito poliuretano de resina de mamona e fibra de ubuçu na fabricação de pisos e revestimentos. Tese (Doutorado). Programa de Pós-graduação em Engenharia de Materiais e de Processos Químicos e Metalúrgicos do Departamento de Engenharia de Materiais do Centro Técnico Científico da PUC-Rio, Rio de Janeiro, 2011.

PORTAL DOS RESÍDUOS SÓLIDOS. Resíduo de papel. Disponível em: $<w w w$.portalresiduossolidos.com/reciclagem-de-papel-2/> Acesso em 12 de maio de 2015.

SAPUAN, S. M.; MALEQUE, M. A. Design and fabrication of natural woven fabric reinforced epoxy composite for household telephone stand. Materials and Design, $v$. 26, p. 65-71, 2005.

SILVA, O. H.; ARDENGHI, T. C.; RITTER, C. M.; SANTOS, F. R.; HALMEMAN, M. C. R. Potencial energético da biomassa da casca de arroz no brasil. In: Simpósio III Ambiental, Paraná: Universidade Tecnológica Federal do Paraná, 2012.

SOUSA, L. K. de. Produção e caracterização mecânica de compósitos de resina poliuretana à base de óleo de mamona e fibras de rami, sisal e bucha vegetal. Dissertação (Mestrado). Faculdade de Engenharia Civil da Universidade Federal de Uberlândia, Uberlândia, 2013.

VILAR, W.D. Química e tecnologia dos poliuretanos. Rio de Janeiro: Vilar, 340p, 1993. 